\title{
11 \\ INTEGRATION OF A CONTRACT FRAMEWORK IN BP MODELS
}

\author{
F. Biennier, J. Favrel \\ INSA de Lyon - Laboratoire PRISMa/IF502 - F69621 Villeurbanne Cédex, FRANCE \\ Frederique.Biennier@insa-lyon.fr \\ Joel.Favrel@insa-lyon.fr
}

\begin{abstract}
To fit economic constraints, enterprises are more and more focused on their own business. This trend involves to renew enterprise organization in order to integrate inter-enterprise partnership. These virtual enterprise organizations require modeling techniques able to take into account inter-enterprise cooperation, flexible and lean enough to be used on "short term" projects and fitting legal constraints as contractual exchanges between enterprises. According to a mid-term point of view, these contracts may include the description of common Business Process (BP) or collaboration rules. Then, each business process enactment may also be related to more specific contracts (orders, invoices...) linked to each enterprise activity. To fit the Virtual Organization requirements, we propose a global architecture coupling $B P$ models and contract frameworks. This architecture is based on the enterprise BP adaptation tofit openness constraints. For this purpose, security requirements are added to the $B P$ specification and the traditional $B P$ organization is split into business transaction. Then generic models describing contractualfacilities and the Virtual Organization collaborative organization are set so that BP enactment (including contract enactment) can be developed.
\end{abstract}

\section{CONTEXT}

Recent changes in the market have led enterprises to overshoot their own borders so that economical partners are considered as members of a same organization. Designed either for a project or for a longer period, the Virtual Enterprise (VE) superimpose its own organization to the partners' own organization. Depending on several factors as the economical context, trust level between partners..., different collaboration policies are used. Consequently, the VE Business Process (BP) specification has to take into account both the BP specification (what has to be done), collaboration policy and contractual requirements (how it may be done) as well as security constraints. Of course, the BP modeling activity should integrate constraints due to the openness involved in virtual organization (this point deals mostly with security policy, re-organization of public and private parts in BP), interenterprise contractual relationships as well as evolving collaboration strategies (section 2). According to an operational point of view, component based architectures based on Enterprise Java Beans (EJB), web services (.net... 
components) or webEDI based on ebXML(electronic business XML) provides open and easy to tune e-business frameworks able to support inter-enterprise collaboration.

To merge these modeling and implementation oriented points of view, we propose a multi-view BP model built incrementally. Modular descriptions of BP are proposed and mix both conceptual (what should be done), organizational (how it must be done) and contractual aspects (section 3) so that BP and their support applications can be easily rebuilt according to the VE current organization.

\section{INTER-ORGANIZATIONS MODELING FRAMEWORK}

Modeling the Virtual Organization business processes involves taking into account the virtual organization specificity, leading to different modeling strategies:

- The VE is considered as a "standard" enterprise: in this case, the modeling activity must fit the virtual enterprise planned duration and protect each enterprise autonomy; several methods have been adapted to this particular context in order to provide a generic modeling framework adapted to the Virtual Enterprise (VE) context (see for example (Tolle et al. 2002) to get a global point of view on the Globemen project and other VE generic modeling frameworks).

- The virtual enterprise is seen as a set of co-operating organizations: in this case the modeling activity must capture the collaborative organization thanks to an interdisciplinary approach (Camarhina-Matos et Pantoja-Lima 2001).

In both cases, the modeling process has to pay a particular attention on the interorganization relationships:

- Inter-enterprise co-ordination can be partly captured with dedicated Business Process models: such workflow-based descriptions (taking into account each partner autonomy) can be build thanks to various methods as IDEFxx as proposed in (Presley et al. 2001) or CIMOSA (Bruno et Torchiano 1999).

- Informal collaboration can not be modeled directly but requires a flexible and open framework. This feature can be set by providing an open information space where the different actors can freely access or exchange the information they need. For this purpose, CORBA based architecture (Zhang et al. 2000) or dedicated distributed frameworks (Sandakly et al. 2001) can be used.

- Distributed collaborative architecture can couple formal and informal cooperation providing that each node integrates formal exchanges (as in an EDI (Electronic Data Interchange) framework) and offers security and co-ordination features as in the PRODNET architecture (Camarinha-Matos et al. 1998).

Moreover, organizing inter-enterprise business processes leads also to different strategies:

- Workflow based strategies can be implemented according to both a distributed or a centralized way. In the distributed strategy, each enterprise can protect its own autonomy thanks to its own workflow definition. In this case, workflow interactions must be defined to provide a global organization (Casati et Di Scenza 2001) and tasks managers must be coordinated thanks to tasks dependency relationships as proposed in the METEOR $_{\mathbf{2}}$ system (Miller et al. 1997). On the other hand, when a centralized organization is set, a common workflow is defined and is turned into activity charts so that a decentralized execution, split among the different partners, can be used. Such an analysis 
process is proposed by (Muth et al. 1998) and makes a heavy use of Transaction Processing systems to provide consistency to the shared information. As a mixed of the previous strategies, a B2B workflow based approach can be derived from traditional EDI (i.e. Electronic Data Interchange) or C-Business environment. For this purpose, (van der Aalst 2002) proposes multiple descriptions of shared business process: public and private workflow are defined concurrently and the global consistency is achieved thanks to well-defined information exchange format (Bussler 2002). By this way collaborative business processes are defined as a set of interconnected private parts (black boxes) for which only the interfaces (inputs and outputs) are known and public parts (white box) with precise process descriptions,

- Component based architectures are derived from a e-Business point of view. Such component based architectures (as Enterprise Java Beans (EJB), web services or web-EDI based on ebXML) provide a flexible and reactive framework, that should be able to support "on-demand" collaboration. Made of basic standard components (a web service, a Java Bean or core components in ebXML (Oasis 2001)), these architectures can be used to provide heterogeneous systems interconnection abilities. For this purpose, core components (i.e. message formats coupled to e-business process description) are defined as reusable and exchangeable information units. As far as ebXML (electronic business XML) is concerned, such E-service infrastructure can be stored in registries so that binding services can set a dynamic workflow ( $\mathrm{Su}$ et al. 2003). Nevertheless, such an open approach involves paying a particular attention to both e-contract enactment used to support inter-enterprise exchanges (Chiu et al. 2002) and on BP consistency. To solve this last problem, BPs are split among transactions, providing information ACID properties (i.e. Atomicity, Consistency, Isolation and Durability) as well as recovery features (Papazoglou 2003).

- Contract based organizations put the stress on the formal and legal relationships between partners. To improve the contract conclusion, a common ontology can be set to describe the different clauses and negotiations organization (Kabilan et al. 2003). Of course, to fit the real process, the interorganization BP specification has to include the contract negotiation phase (Cheung et al. 2002a) and the business process execution must be related to the contractual obligation clauses (answering mostly the who, what, when and how parameters) (Perrin et Godart 2003). Nevertheless, e-contract based frameworks are mostly limited to elementary business transactions (Heuvel et Weigand 2003) and do not integrate the global Virtual Organization context.

Nevertheless, none of these different strategies fit the inter-enterprise BP modeling requirements. In order to overcome these limits, a global process modeling strategy has to be set according to the following main requirements:

- The BP organization has to take into account constraints due to the system openness i.e. paying a particular attention to the enterprise intangible patrimony (process public or private parts, information classification...) according to a consistent security policy definition.

- The modeling framework has to take into account the evolving collaboration strategy between partners. Consequently, BPs should be rather seen as consistent set of components and assembly rules instead of a unique process specification. 
Thanks to this component based approach, the BP engineering phase can be reduced to fit the VE limited duration.

- Formal inter-enterprise relationships described thanks to contracts should be integrated into the BP organization, setting obligations, synchronization requirements... This contractual framework can also be used as a generic guideline to select convenient components assembly to fit the required BP.

\section{FROM ENTERPRISE BP TO INTER-ENTERPRISE BP MODELS}

VEs require a lean and evolving structure, able to protect the flexibility and reactivity of each partner. Moreover, enterprise-engineering projects are rather long and their cost can be a bar. This can be overcome by connecting engineering processes to more efficient diagnostic processes to guide the way standard solutions are chosen. Such a bottom-up modeling approach proposed in the GRECOPME framework (Biennier et al. 2002) relies both on an efficient "collaboration" diagnosis and on re-usable collaborative business processes. Of course, in order to preserve each enterprise autonomy and to favor the emergence of the global synergy, collaborative Business Processes have to be adapted to this multi-enterprises context. That is why we proposed to re-organize the Business Process description to capture "generic" collaboration patterns. By this way, the BP can evolve continuously and the VE evolution can be taken into account directly in the modeling framework (Biennier et Favrel 2003). Moreover, to favor inter-enterprise BP enactment, we propose a multi-facet architecture built incrementally:

- First, enterprise business process have to be adapted to integrate the VE openness constraint. Such cross-organizational process definition involves to focus on the enterprise patrimony constraints, i.e. integrating privacy requirements on both knowledge (information and current activity) and know how (process tuning). To fit this requirement, a multi-level BP description (including public and private parts, detailed "interface" specification...) coupled to a security organization is set.

- Second, the inter-enterprises relationships are taken into account by adding collaboration strategies into the inter-enterprise BP specification. This is mostly used for short or mid term collaboration (and not for instant VE as developed in B2B online relationship). Then, contract models and clause are coupled to the BP specification and collaboration management task. This allow to relate particular clauses to a convenient set of elementary e-contract.

- Third inter-enterprise BP enactment is improved thanks to multiple inheritance from the generic models developed previously. Then an authentication service is used to provide both authentication and non repudiation features (involved in econtract management) without breaking data privacy constraints.

\subsection{Integration of the VE constraints in the enterprise BP models}

The first step of the BP re-design approach consists in defining how the enterprise information system and BP organization can be shared according to two main axis:

- The BP conceptual definition is adapted to support a cross-organizational integration. For this purpose, we propose a recursive definition (a BP is a set of 
tasks and a task may also be defined as a BP) so that a multi-level BP organization can emerge, integrating both private and public parts. To fit BP interconnection requirements, BP are re-organized into Business Transaction (including also the recursive way). These transactions represent the BP interface specification and are associated to a consistent part of the BP that can be included into a cross organization $\mathrm{BP}$ and can be configured according to negotiated parameters. Core processes, that can be related to elementary core components, web services or EJBs, are related to elementary tasks. By this way, this generic and conceptual architecture can be related to existing frameworks to derive convenient BP implementation.

- A security policy is defined according to a patrimonial analysis of both the information pieces and of the tasks included in the business process. These patrimonial values are related to protection rules used by Information System Security Officers (ISSO) responsible of the protected item to control security processes organization (security workflow), mostly devoted to access control and authentication. Of course, items security classification is also managed thanks to a global security workflow describing the enterprise general security policy. Then, these security workflow are integrated in the BP conceptual definition so that the security constraints can be easily taken into account.

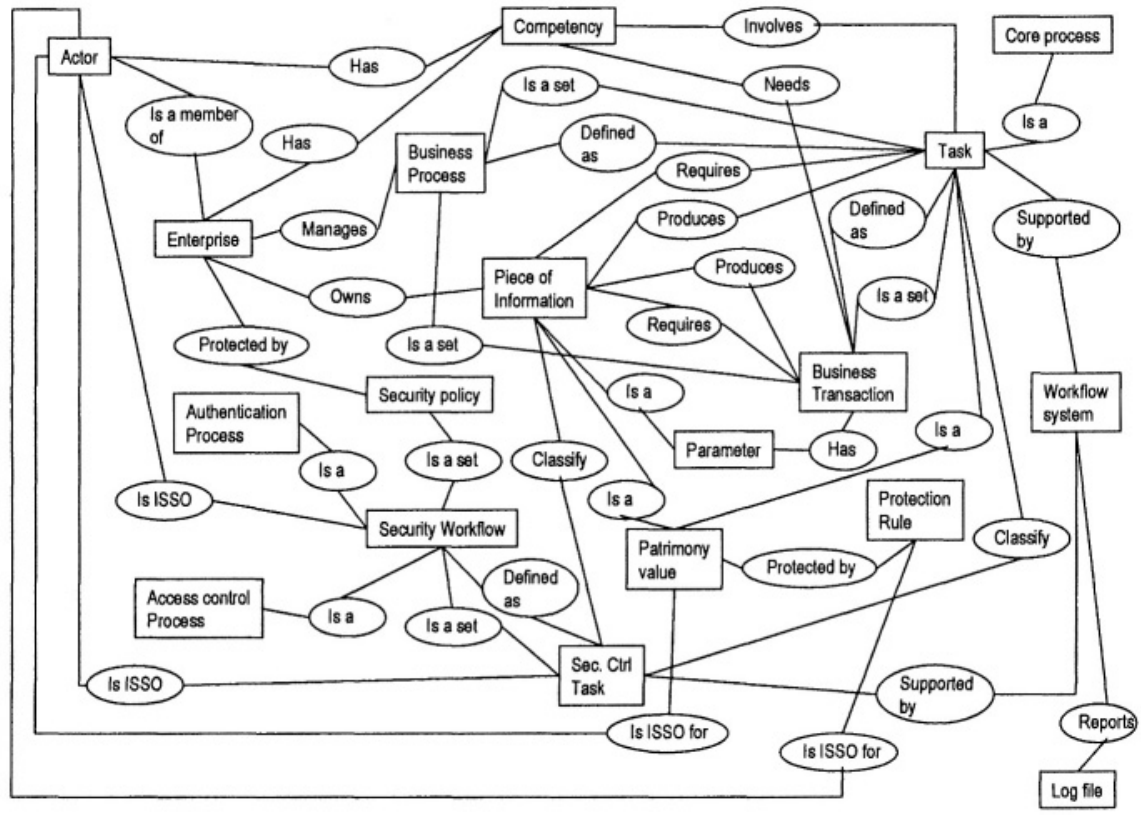

Figure 1: Enterprise BP adaptation to fit openness constraints

\subsection{Inter-enterprise BP organization}

The cross-organizational BP modeling approach has to be adapted to the VE organization strategy and its potential evolution. Moreover, the inter-enterprise BP specification must also integrate contractual relationships.

To fit the collaboration evolution constraint, we propose to re-organize the BP description to capture "generic" collaboration patterns. For this purpose, the 
recursive enterprise BP model we presented previously mixes both "black box" and "white box" BP specifications. Thanks to the "business transaction" the collaborative business processes can be coupled precisely to the different partners own business processes. Then, organizational constraints are taken into account. For this purpose, collaboration workflow describing the VE collaboration management processes is added in the BP model. By this way conceptual BPs are derived into organizational ones specifying how inter-enterprise BPs have to be executed (Biennier et Favrel 2003).

Then, contractual relationships are taken into account by coupling a contract framework to the BP specification. This framework inspired from (Karlapalem et al. 2001) relates contract clauses to economic activities (business transaction in our case) but we extend this framework to integrate both the VE collaboration policy (related to collaboration workflow), security policies requirements (related to security workflow). Used as a generic guideline, these generic contracts may also include a variable part as proposed in (Cheung et al. 2002b) related to the business transaction configuration achieved during BP negotiation. Lastly, at an operational level, contract clauses can be implemented as a set of e-contracts. For this purpose, we use the business transaction related to a particular contractual clause (for example orders, payment...) as en entry point to define the elementary tasks and core processes involved. Then these core processes are used to define the related econtracts that must be set to fulfilled the global contractual agreement

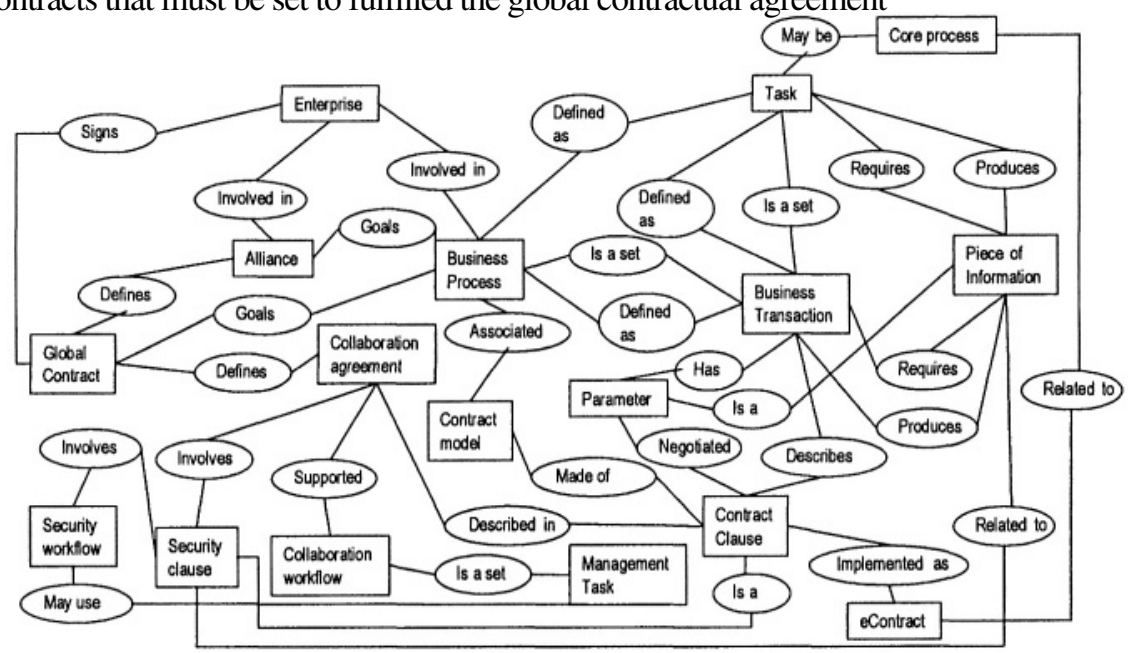

Figure 2: Inter-enterprise Business Model

\subsection{Cross-organizational BP enactment}

Lastly, these generic models are used to generate global templates for real BP. According to this enactment process, every parameters have to be valued and actors must be related to the different tasks the have to achieved. To fit inter-enterprise interchange constraints, authentication and non repudiation features must be provided. These constraints, as well as those due to the security policies specification, involve to identify each actor and report his activities. This last point can be seen as a contradiction with data privacy legal constraints. To solve this problem, we add an authentication service coupled to an access control process. 
Thanks to the BP generic definition, tokens are given to actors to achieve a particular task. This token is also used by the access control system to allow the actor involved in a task to accede to the related information. Then only these "authenticated user" identifications are transmitted to the BP reporting system. As each authentication identification is given separately, the different tasks involving a same actor can not be directly related by the BP reporting system so that data privacy fair practices can be fit. At a technical level, the authenticated users are created and "forward" links are made between these "authenticated user account" and the real actor account.

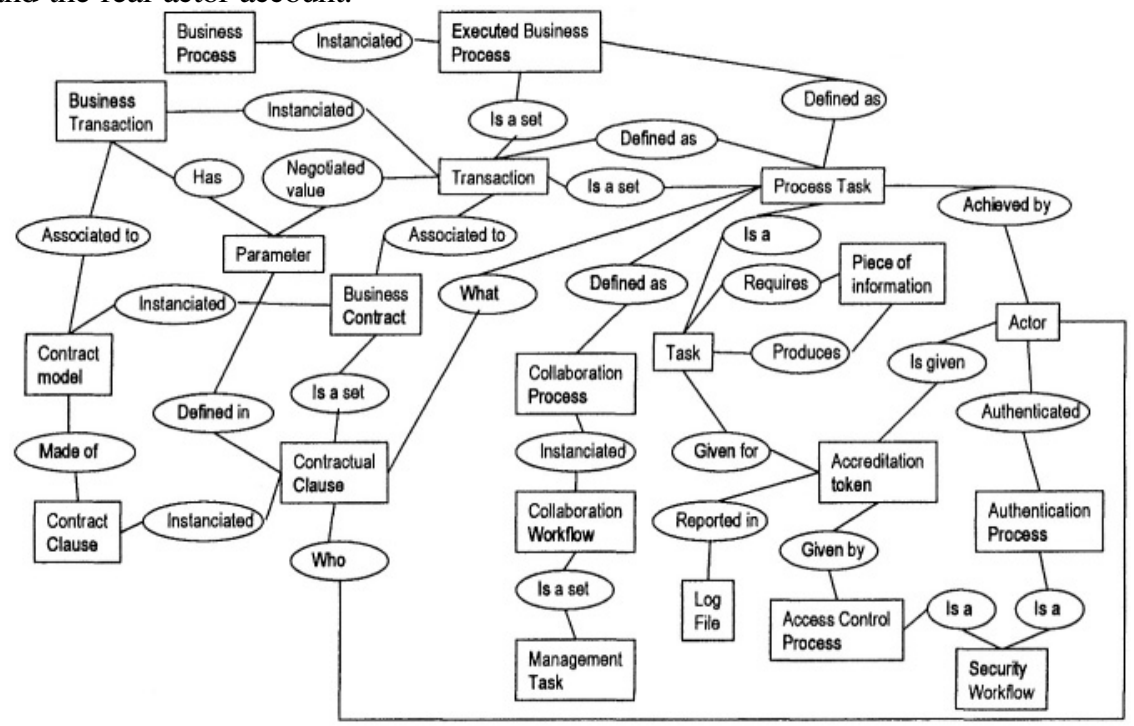

Figure 3: BP Enactment model

\section{CONCLUSION AND FURTHER WORKS}

Modeling cross-organizational business processes involve taking into account the way partners aim to collaborate, how the common BP can be related to the existing partners own BPs, security policies as well as contract formalization. We propose here to integrate these different points of view by adapting each partner BP definition to the VE context. Then generic BP, collaboration patterns and contract models can be defined so that the inter-enterprise BP enactment (including contract definition) can be improved. Nevertheless, our architecture leads to a multiple workflow organization for the BP (security workflow, collaboration workflow, BP workflow...) so that cross-validation must be defined to control the global consistency.

\section{REFERENCES}

1. van der Aalst W., 2002. Inheritance of inter-organizational workflows to enable business to business E-commerce. Electronic commerce research (2). pp. 195-231 
2. Biennier F., Boucher X., Hammami A., Vincent L., 2002. Towards a modelling framework for networks of SMEs. Collaborative business ecosystems and virtual enterprises, Camarinha-Matos L. Ed. Kluwer academic publishers, pp. 11-18.

3. Biennier F., Favrel J., 2003. Collaborative BP engineering in alliances of SMEs. Processes and foundations for virtual organizations. Camarinha-Matos L., Afsarmanesh H., Ed. Kluwer academic publishers, pp. 441-448

4. Bruno G., Torchiano M., 1999. Making CIMOSA operational: the experience with PrimeObjects tool. Computers in industry (40). pp. 279-291

5. Bussler C., 2002. The application of workflow technology in semantic B2B integration. Distributed and parallel databases (12). pp. 163-191

6. Camarinha-Matos L.M., Afsarmanesh H., Garita C., Lima C., 1998. Towards an architecture for virtual enterprises. Journal of intelligent Manufacturing (9). pp. 189-199

7. Camarinha-Matos L. M., Pantoja-Lima C., 2001. Cooperation coordination in virtual enterprises. Journal of intelligent manufacturing (12). pp. 133-150.

8. Casati F., Discenza A., 2001. Modeling and managing interactions among business processes. Journal of systems integration (10). pp. 145-168.

9. Cheung S.C., Chiu D.K.W., Till S., 2002a. A three layer framework for cross-organisational econtract enactment. Lecture Notes in Computer Science 2512, pp. 78-92

10. Cheung S.C., Hung P.C.K., Chiu D.K.W., 2002b. A meta model for e-contract template variable dependencies facilitating -e-Negotiation. Lecture Notes in Computer Science 2503, pp. 50-64

11. Chiu D.K.W., Karlapalem K., Li Q., Kafeza E., 2002. Workflow view based e-contracts in a cross organizational e-services environment. Distributed and parallel databases (12). pp. 193-216

12. Van den Heuvel W.J., Weigand H., 2003. Coordinating web-services enabled business transactions with contracts. Lecture Notes in Computer Science 2681, pp. 568-583

13. Kabilan V., Johannesson P., Rugaimukamu D.M., 2003. Business contract obligation monitoring through use of multi-tier contract ontology. Lecture Notes in Computer Science 2889, pp. 690-702

14. Karlapalem K., Dani A.R., Radha Krishna P., 2001. A framework for modeling electronic contracts. Lecture Notes in Computer Science 2224, pp. 193-207

15. Miller J.A., Palaniswami D., Sheth A.P., Kochut K.J., Singh H., 1997. WebWork: Meteor's Webbased workflow management system. Journal of intelligent information system (10). pp. 185-213

16. Muth P., Wodtke D., Weissenfels J., Kotz Dittrich A., Weikum G., 1998. From centralized workflow specification to distributed workflow execution. Journal of intelligent information system (10). pp. 159-184

17. Oasis 2001. Business Process and Business Information analysis overview v1 .0. 40 pages. Available at http://www.ebxml.org/specs/bpOVER.pdf

18. PapazoglouM.P., 2003. Web services and Business transactions. World Wide Web: Internet and Web information systems (6). pp. 49-91

19. Perrin O., Godart C., 2003. A contract model to deploy and control cooperative processes. Lecture Notes in Computer Science 2819, pp. 78-90

20. Presley A., Sarkis J., Barnett W., Liles D., 2001. Engineering the virtual enterprise: an architecturedriven approach. The international journal of flexible manufacturing systems (13). pp. 145-162. Kluwer academic publishers

21. Sandakly F., Garcia J., Ferreira P., Poyet P., 2001. Distributed shared memory infrastructure for virtual enterprise in building and construction. Journal of Intelligent manufacturing 12). pp. 199-212

22. Su S.Y.W., Meng J., Krothivasan R., Degwekar S., Helal S., 2003. Dynamic inter-entreprise workflow management in a constraint based E-service infrastructure. Electronic commerce research (3). pp. 9-24

23. Tolle M., Bernus P., Vesterager J., 2002. Reference models for vitual enterprises. Collaborative business ecosystems and virtual enterprises, Camarinha-Matos L. Ed. Kluwer academic publishers, pp. 3-10

24. Zhang Y.P., Zhang C.C., Wang H.P., 2000. An internet based STEP data exchange framework for virtual enterprises. Computers in industry (41). pp. 51-63 